\title{
Developing a Method for Assessing Environmental Sustainability Based on the Google Earth Engine Platform
}

\section{Xianwang Xia}

Beijing Normal University

\section{Chentai Jiao}

Beijing Normal University

\section{Shixiong Song}

Zhejiang Sci-Tech University

\section{Ling Zhang}

Beijing Normal University

\section{Xingyun Feng}

Beijing Normal University

Qingxu Huang ( $\nabla$ qxhuang@bnu.edu.cn )

Beijing Normal University https://orcid.org/0000-0003-4902-716X

\section{Research Article}

Keywords: Google Earth Engine, remote sensing big data, urban sustainability, Jing-Jin-Ji urban agglomeration, ecological civilization

Posted Date: November 18th, 2021

DOl: https://doi.org/10.21203/rs.3.rs-1009482/v1

License: (c) (i) This work is licensed under a Creative Commons Attribution 4.0 International License.

Read Full License

Version of Record: A version of this preprint was published at Environmental Science and Pollution Research on March 29th, 2022. See the published version at https://doi.org/10.1007/s11356-022-19773z. 


\title{
Developing a method for assessing environmental sustainability based on the Google Earth Engine platform
}

\author{
Xianwang Xia ${ }^{\text {a }}$, Chentai Jiao ${ }^{\text {a }}$, Shixiong Song ${ }^{\text {c, d }}$, Ling Zhang a, b, Xingyun Feng a , \\ Qingxu Huang ${ }^{\text {a, }}$, * \\ ${ }^{a}$ Center for Human-Environment System Sustainability (CHESS), State Key Laboratory of Earth \\ Surface Processes and Resource Ecology (ESPRE), Faculty of Geographical Science, Beijing \\ Normal University, Beijing 100875, China \\ ${ }^{\mathrm{b}}$ School of Natural Resources, Faculty of Geographical Science, Beijing Normal University, \\ Beijing 100875, China \\ c School of Economics and Management, Zhejiang Sci-Tech University, Hangzhou 310018, \\ Zhejiang, China \\ d Zhejiang Academy of Eco-Civilization, Zhejiang Sci-Tech University, Hangzhou 310018, \\ Zhejiang, China
}

\section{Contact information:}

\section{Xianwang Xia}

Xinjiekouwai Street No. 19, Haidian District, Beijing 100875, CN; Email: 201811940123@ mail.bnu.edu.cn; Tel.: +86-13-31263-1925.

\section{Chentai Jiao}

Xinjiekouwai Street No. 19, Haidian District, Beijing 100875, CN; Email: 201811051114@mail.bnu.edu.cn; Tel.: +86-15-55286-0566.

\section{Shixiong Song}

928 Second Avenue, Xiasha Higher Education Zone, Hangzhou, China, 310018, Email: songsx@zstu.edu.cn; Tel.: +86-18-81157-3257.

\section{Ling Zhang}

Xinjiekouwai Street No. 19, Haidian District, Beijing 100875, CN; Email: LingZhang@mail.bnu.edu.cn; Tel.: +86-18-80137-5491.

\section{Xingyun Feng}

Xinjiekouwai Street No. 19, Haidian District, Beijing 100875, CN; Email: fxy1728@outlook.com; Tel.: +86- 15-80865-9574.

\section{Qingxu Huang}

Xinjiekouwai Street No. 19, Haidian District, Beijing 100875, CN; Email: qxhuang@bnu.edu.cn; Tel.: +86-18-61220-7978.

* Corresponding author at: State Key Laboratory of Earth Surface Processes and Resource Ecology, Beijing Normal University, 19 Xinjiekouwai Street, Beijing 100875, China. Email: qxhuang@bnu.edu.cn; Tel.: +86-18-61220-7978. 


\title{
Developing a method for assessing environmental sustainability based on the Google Earth Engine platform
}

\begin{abstract}
Environmental sustainability is the foundation and of great significance for the sustainable development of urban agglomerations. Taking the Beijing-Tianjin-Hebei urban agglomeration as an example, we developed a method to effectively assess long-term regional environmental sustainability based on the Google Earth Engine (GEE) platform. We used the GEE to obtain 5206 Landsat remote sensing images in the region from 1983 to 2016 and developed the comprehensive environmental index (CEI) to assess regional environmental sustainability based on the theme-oriented framework proposed by the United Nations Commission on Sustainable Development. We found that the environmental sustainability of the urban agglomeration showed a trend of first rising, then falling, and then rising again in the past 30 years. The average CEI increased from 0.621 to 0.631 from 1985 to 1990, dropped to the lowest value of 0.618 in 2000, and then rose to the highest value of 0.672 in 2015. In particular, the extent of areas in which environmental sustainability improved (56\% of the region) was greater than the extent of areas in which environmental deterioration occurred. The environmental sustainability of Hengshui, Xingtai and Cangzhou in the southeast of the region has been significantly improved. The method proposed in this study provides an automatic, rapid and extensible way to assess regional environmental sustainability and provides a scientific reference for improving the sustainability of the regional ecological environment.
\end{abstract}

Key words: Google Earth Engine; remote sensing big data; urban sustainability; Jing-Jin-Ji urban agglomeration; ecological civilization

\section{Introduction}

Sustainability is related to human survival and development and is a hot topic in the 21 st century. Regional sustainability refers to the societal, economic and environmental development that meet the developmental needs of contemporary people but do not damage the development of future generations and other regions (Brundtland et al., 1987). Among the three dimensions of sustainability (i.e., societal, economic and environmental sustainability), environmental sustainability is the basis of regional sustainability and guarantees social sustainability and economic sustainability (Wu, 2013; Olafsson et al., 2014). Therefore, assessing regional environmental sustainability and its dynamic characteristics in time and space is important for achieving regional sustainable development.

In recent years, remote sensing has played an increasingly important role in regional environmental sustainability assessment studies. A recent review found that approximately $18 \%$ of more than 230 indicators used to assess global sustainable development make direct or indirect use of remote sensing monitoring data (Estoque, 2020). Remote sensing can provide a macroscopic and scientific data basis for environmental sustainability monitoring because it can acquire satellite monitoring data over a large area quickly and with high accuracy (Ustin, 2004; Wang, 2021). For example, Sutton (2003) developed the environmental sustainability index based on nighttime lighting data and land cover data to assess global environmental sustainability in 2001. Similarly, Xu (2013a) developed the remote sensing ecological index (RSEI) using Landsat images to assess urban environmental sustainability in Fuzhou, China, from 2001 to 2009. More recently, Shruti (2021) developed the smart city environmental sustainability index based on 24 environmental indicators to assess environmental sustainability in the construction of new 
smart cities. Although remote sensing-based means provide effective methods for monitoring and assessing environmental sustainability, limitations such as large data volume, heavy preprocessing work, and low efficiency of exponential calculation still exist, making them difficult to implement at large spatial scales or over a long-term scale.

The Google Earth Engine (GEE) platform provides a convenient way to process massive and complex remote sensing data. First, the GEE provides online access to remote sensing data from different satellites and scales around the world, including over 30 years of historical images and datasets, breaking the limitation of data downloading and local data storage. Second, the GEE has various algorithm interfaces, such as cloud masks, radiometric correction and mountain shadow correction, so that remote sensing data can be easily and quickly preprocessed. In addition, the GEE is a cloud service platform that is able to perform exponential parallel computing on the Google Cloud, which greatly improves the data processing efficiency. With the Google Cloud, the GEE has a great advantage in the integration and computation of big data (Mateo-García, 2018). For example, Hansen (2013) used 654,178 Landsat 7 remote sensing images approximately $707 \mathrm{~TB}$ in size to monitor forest cover change at the global scale. This data would take $10^{6}$ hours to preprocess on an ordinary personal computer and only 100 hours to preprocess through accessing and computing online using the GEE. Therefore, it is expected that studies can monitor regional ecological environment sustainability on a large scale and long-term scale using the strengths of the GEE.

The purpose of our study is to develop the comprehensive environmental index (CEI) based on the GEE for the rapid assessment of regional environmental sustainability. Taking the Beijing-Tianjin-Hebei urban agglomeration as an example, we assessed the dynamic characteristics of its environmental sustainability over the last 30 years. First, we used the GEE to acquire Landsat images in the study area for the summers of 1985-2015. Then, based upon the theme-oriented framework proposed by the United Nations Commission on Sustainable Development (UNCSD), we developed the CEI using four indicators: greenness (representing vegetation), wetness (representing soil moisture), heat (representing temperature), and dryness (representing built area). Finally, we analyzed the spatial and temporal dynamic characteristics of environmental sustainability in the Beijing-Tianjin-Hebei urban agglomeration from 1985-2015, which can provide a scientific reference for regional sustainable development.

\section{Study area and data sources}

\subsection{Study area}

The Beijing-Tianjin-Hebei urban agglomeration is located at $113^{\circ} 27^{\prime} \mathrm{E}-119^{\circ} 50^{\prime} \mathrm{E}$ and $35^{\circ} 03^{\prime} \mathrm{N}$ $42^{\circ} 40^{\prime} \mathrm{N}$ in the northern part of the North China Plain. The agglomeration borders the Bohai Sea to the east, the Huang-Huai Plain to the south, the Taihang Mountains to the west, and the Mongolian Plateau to the north. The agglomeration has a typical temperate continental monsoon climate zone. The average annual temperature rises gradually from north to south, while precipitation is unevenly distributed and mostly concentrated in summer (Fig. 1). The Beijing-Tianjin-Hebei urban agglomeration covers an area of approximately $210,000 \mathrm{~km}^{2}$. The agglomeration includes the two municipalities of Beijing and Tianjin and 11 prefecture-level cities in Hebei Province: Zhangjiakou, Chengde, Qinhuangdao, Tangshan, Cangzhou, Hengshui, Langfang, Baoding, Shijiazhuang, Xingtai, and Handan. Since China's reform and opening up, the study area has experienced rapid economic growth and urbanization, and the conflict between environmental protection and urban construction has also intensified. Therefore, the agglomeration has been a key area for ecological environment construction (Wang et al., 2019). 


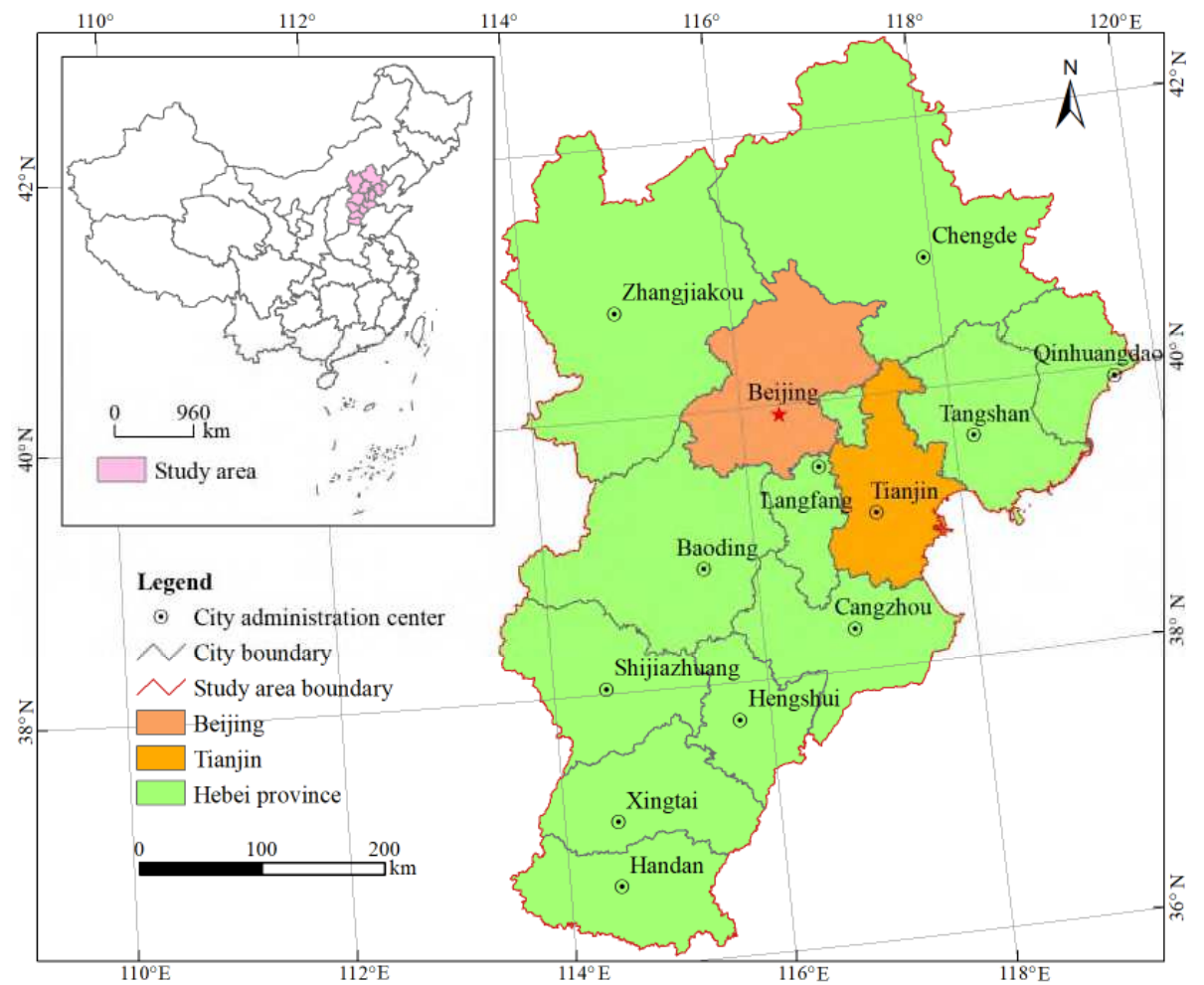

Fig. 1. The Beijing-Tianjin-Hebei urban agglomeration.

\subsection{Data sources}

The data used in this study include four main types, namely, Landsat satellite remote sensing images, atmospheric water content data, surface emissivity data and Beijing-Tianjin-Hebei region vector administrative boundary data. Landsat satellite data were obtained from the United States Geological Survey (USGS). We used satellite remote sensing imageries of Landsat 5 TM from 1984 to 2011 and Landsat 8 OLI from 2014 to 2016, both with a spatial resolution of $30 \mathrm{~m}$. Specifically, the surface reflectance datasets were Landsat 5 Surface Reflectance Tier 1, Landsat 8 Surface Reflectance Tier 1, Landsat 5 TM Collection 1 Tier 1 TOA Reflectance, and Landsat 8 Collection 1 Tier 1 TOA Reflectance (https://developers.google.com/earth-engine/datasets/catalog). After 2003, the scan line corrector (SLC) of the Landsat 7 satellite failed, resulting in approximately $22 \%$ of the data being corrupted (Zhu et al., 2010). Therefore, we did not use Landsat 7 satellite data in this study. Atmospheric water content data were obtained from the NCEP/NCAR Atmospheric Reanalysis Data jointly produced by the National Centers for Environmental Prediction (NCEP) and the National Center for Atmospheric Research (NCAR). The surface emissivity data are derived from ASTER-GED (AG100: ASTER Global Emissivity Dataset 100-meter V003), a global surface emissivity dataset with a spatial resolution of 100 meters published by NASA. In addition, the administrative boundary vector data of the Beijing-Tianjin-Hebei urban agglomeration were obtained from the Resource Environment Science and Data Center, Institute of Geographical Sciences and Natural Resources Research, Chinese Academy of Sciences (www.resdc.cn/Default.aspx).

\section{Methods}

In this study, we quantified and analyzed the environmental sustainability of the Beijing-TianjinHebei urban agglomeration over the past 30 years using the GEE platform (Fig. 2). First, we accessed Landsat 5/8 surface reflectance images online using the GEE for the corresponding study years and 
preprocessed the images with cloud masking, stitching, and integration. Then, based on the sustainability assessment framework proposed by the UNCSD, we selected and calculated four indices representing four dimensions of ecological environment quality: the NDVI (normalized difference vegetation index) for greenness, the NDBSI (normalized difference build and soil index) for dryness, WET for wetness, and LST (land surface temperatures) for heat (UNDP, 2014). In addition, we calculated the modified normalized difference water index (MNDWI) for water masking. After water masking and normalization of the four indicators, we developed the CEI according to Xu (2013a) and He (2017). Finally, combining regional statistics and change detection, we analyzed the characteristics of the variation in environmental sustainability in the Beijing-Tianjin-Hebei urban agglomeration from 1985 to 2015 and the spatial distribution characteristics in the region.

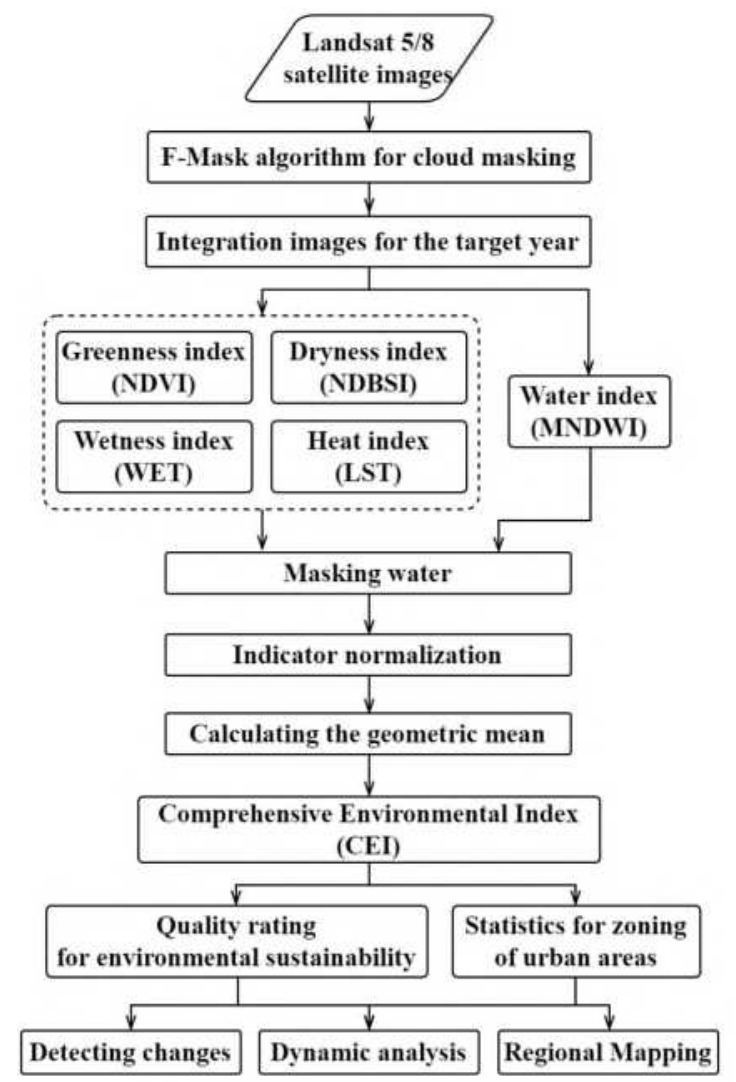

Fig. 2. Flowchart for quantifying and analyzing regional environmental sustainability

\subsection{Selecting images}

We selected seven time points from 1985 to 2015 including 1985, 1990, 1995, 2000, 2005, 2010, and 2015. The integrated images for each time point, except for 1985, are synthesized from remote sensing images of the summer (from June 1 to September 30) of three years, including the current year, the previous year, and the year after. Because of the lack of images from 1984 to 1986, we used remote sensing images in the summers from 1983 to 1987 to synthesize the target images for 1985. Finally, we used 5206 remote sensing images of Landsat 5 TM and Landsat 8 OLI between 1983 and 2016 (Fig. 3). In GEE, we first filtered the remote sensing images in the time range of the target year and then used the cloud mask function provided by the GEE to mask the clouds of images from different satellites. Because of the frequent cloud cover in remote sensing images during summer, we used median pixel-by-pixel synthesis in image integration to avoid low quality images (Midekisa et al., 2017). According to Fig. 3, there are 25 image cells covering the Beijing-Tianjin-Hebei region, the number of images used for each 
Landsat tile in this study is not less than 118, and the number of images for each study year is not less than 539.

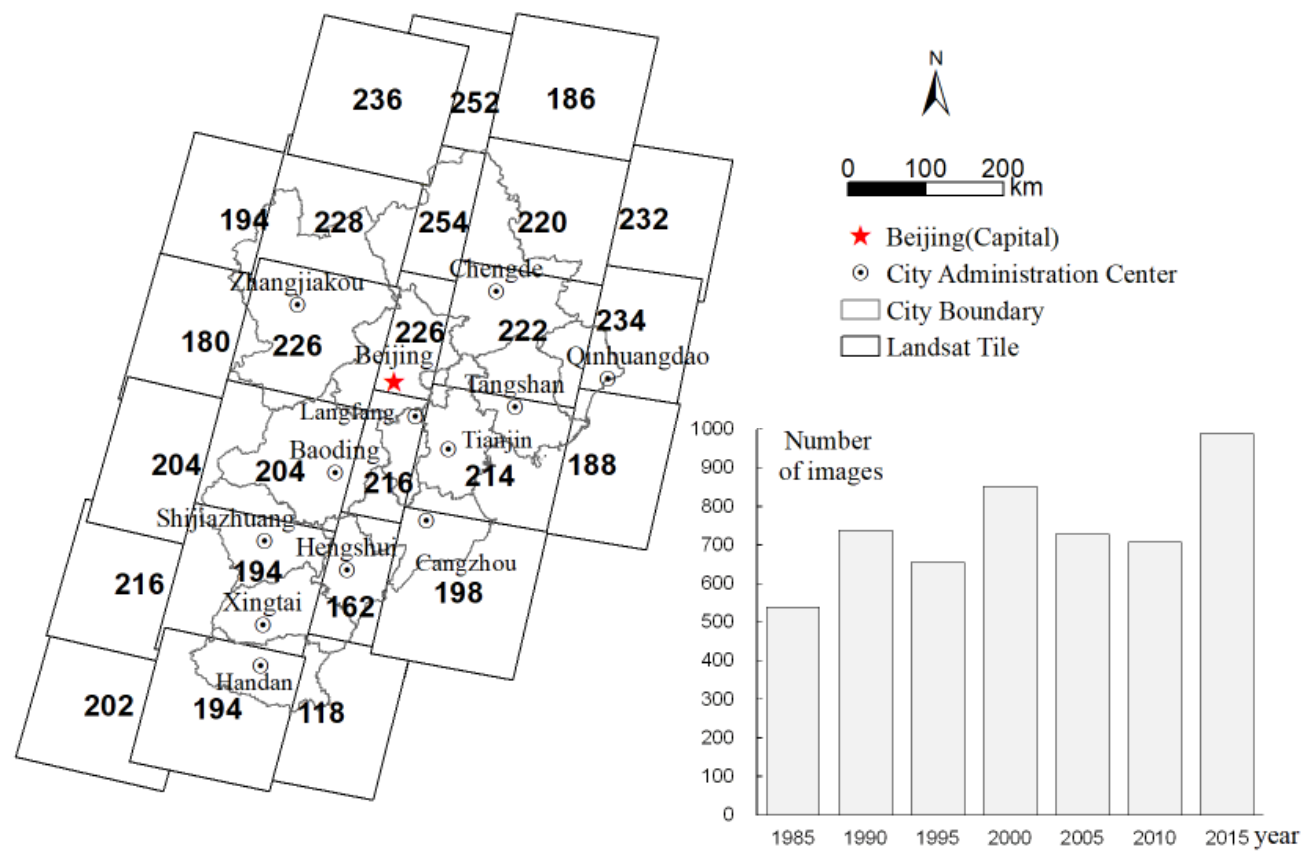

Fig. 3. Distribution of the number of Landsat images used.

Note: The numbers are the sums of the images used per Landsat tile.

\subsection{Developing the comprehensive environmental index}

We developed the CEI based on the sustainability assessment framework proposed by the UNCSD. The framework identifies five major environmental themes to ensure that environmental sustainability is assessed in multiple dimensions: water (water quality and water quantity), land (cropland, vegetation, desertification, and urbanization), atmosphere (air quality, ozone layer depletion, and climate change), biodiversity (ecosystems and species), and oceans (fisheries and coastal zones) (UN, 2007). According to this framework, $\mathrm{Xu}$ (2013a) and He (2017), we used the indicators of four dimensions, greenness, dryness, humidity, and heat, to represent vegetation, desertification, surface moisture status, and urban heat island conditions, respectively. These indicators are strongly correlated with water, land, atmosphere, and biodiversity in the framework. The CEI is the geometric mean of these four indicators:

$$
C E I=\sqrt[4]{(N D V I+0.01) \times(N D B S I+0.01) \times(W E T+0.01) \times(L S T+0.01)}
$$

where NDVI, NDBSI, WET, and LST represent the greenness, dryness, wetness, and heat indices after normalization. The calculated CEI ranged from 0.01 to 1.01 , which directly represents regional environmental sustainability. When the CEI is closer to 1.01 , the better environmental sustainability of the study area is better.

\subsubsection{Calculating the four indices}

First, we used the NDVI to represent the greenness index. The NDVI is closely related to vegetation biomass and the leaf area index (Goward et al., 2002); therefore, it can be a good indicator of the cover, diversity, and growth of surface vegetation, as well as an indicator of changes in surface land use and 
land cover (Gandhi et al., 2015; Fairbanks et al., 2004. Senay et al., 2000). The NVDI is calculated as:

$$
N D V I=\frac{\rho_{N I R}-\rho_{R}}{\rho_{N I R}+\rho_{R}}
$$

Second, the dryness index is the average of the soil index (SI) and index-based built-up index (IBI) used to characterize the "dryness" of the ground surface (Xu, 2008; Rikimaru et al., 2002). The dryness index characterizes the land in the region that is not covered by vegetation or has an excavated surface, and it is strongly associated with human urban construction activities (Hu et al., 2018). The dryness index is calculated as:

$$
N D B S I=\frac{S I+I B I}{2}
$$

The SI and IBI were calculated using the following two formulas (Rikimaru et al., 2002; Xu, 2008):

$$
\begin{gathered}
S I=\left[\left(\rho_{S W I R 1}+\rho_{R}\right)-\left(\rho_{N I R}+\rho_{B}\right)\right] /\left[\left(\rho_{S W I R 1}+\rho_{R}\right)+\left(\rho_{N I R}+\rho_{B}\right)\right] \\
I B I=\left\{2 \rho_{S W I R 1} /\left(\rho_{S W I R 1}+\rho_{N I R}\right)-\left[\rho_{N I R} /\left(\rho_{N I R}+\rho_{R}\right)+\rho_{G} /\left(\rho_{G}+\rho_{S W I R 1}\right)\right]\right\} \\
/\left\{2 \rho_{S W I R 1} /\left(\rho_{S W I R 1}+\rho_{N I R}\right)+\left[\rho_{N I R} /\left(\rho_{N I R}+\rho_{R}\right)+\rho_{G} /\left(\rho_{G}+\rho_{S W I R 1}\right)\right]\right\}
\end{gathered}
$$

Third, the wetness index represents the moisture status of the observed surface and is closely related to surface water, vegetation moisture and soil moisture (Xu, 2013b). Therefore, we used the wet component obtained from a tasseled cap transformation to characterize the wetness index, and the wetness index was calculated using the following formulas for Landsat 5 TM and Landsat 8 OLI (Crist, 1985; Baig et al., 2014):

$$
\begin{aligned}
& W E T=0.0315 \rho_{B}+0.2021 \rho_{G}+0.3102 \rho_{R}+0.1594 \rho_{\text {NIR }}-0.6806 \rho_{\text {SWIR } 1}-0.6109 \rho_{\text {SWIR } 2} \\
& W E T=0.1511 \rho_{B}+0.1973 \rho_{G}+0.3283 \rho_{R}+0.3407 \rho_{\text {NIR }}-0.7117 \rho_{\text {SWIR } 1}-0.4559 \rho_{\text {SWIR } 2}
\end{aligned}
$$

In the above formulas, $\rho_{B}, \rho_{G}, \rho_{R}, \rho_{N I R}, \rho_{S W I R 1}$, and $\rho_{S W I R 2}$ are the reflectances in the blue, green, red, near-infrared, shortwave infrared 1, and shortwave infrared 2 bands from Landsat TM and Landsat 8 OLI satellites, respectively.

Finally, thermal pollution, such as the urban heat island effect that is becoming increasingly more important in urban environment monitoring, has become significant environmental pollution. Therefore, it is necessary to introduce a heat index to develop the CEI (Xu, 2013c). In this study, we used the LST obtained from the inversion of remote sensing images as a heat index. Based on the mono-window algorithm for surface temperature proposed by Duguay-Tetzlaff et al. (2015), Ermida et al. (2020) achieved automated surface temperature, which can automatically invert the surface temperature of a single remote sensing image, using the GEE platform. In our study, we used the average atmospheric water content of the target year to represent the atmospheric water content value of the integrated image. Using this method, we achieved the inversion of the land surface temperature of integrated images.

\subsubsection{Masking water}

In order to avoid the disturbance of the surface moisture from the ocean in coastal areas or large water bodies in the Beijing-Tianjin-Hebei region, we used MNDWI to identify large areas of water. Based on the MNDWI, we ran the water mask algorithm for the NDVI, NDBSI, WET, and LST (Xu, 2005). The MNDWI is calculated using the following formula:

$$
M N D W I=\frac{\rho_{G}-\rho_{S W I R 1}}{\rho_{G}+\rho_{S W I R 1}}
$$




\subsubsection{Normalizing the four indices}

In order to eliminate the differences in indicators and enhance comparability between different years, it is necessary to normalize each indicator $(\mathrm{Xu}, 2013 \mathrm{c})$. The normalization calculation formulas are as follows:

$$
\begin{aligned}
& y_{i 1}=\frac{x_{i}-x_{\min }}{x_{\max }-x_{\min }} \\
& y_{i 2}=\frac{x_{\max }-x_{i}}{x_{\max }-x_{\min }}
\end{aligned}
$$

where $x_{i}$ is the value of the image pixel $i . x_{\max }$ is the maximum value of $x_{i}$, and $x_{\min }$ is the minimum value of $x_{i}$. After screening out the image element outliers, the maximum and minimum values can be determined. $y_{i 1}$ is the normalization formula for positive indicators, and $y_{i 2}$ is the normalization method for negative indicators (Liu and Hao, 2017). According to Xu (2013a), greenness and humidity play a positive roles and dryness and heat play negative roles in environmental sustainability. Therefore, the NDVI and WET used formula $y_{i 1}$ and the NDBSI and LST used formula $y_{i 2}$ to calculate the normalized results.

\subsection{Quantifying the spatial and temporal dynamics of environmental sustainability}

\subsubsection{Static characteristics}

Considering the distribution characteristics of the CEI at seven time points from 1985 to 2015 and referring to the mean and standard deviation of the CEI, we divided the CEI into the five classes of 0$0.52,0.52-0.59,0.59-0.65,0.65-0.71$, and $0.71-1$, which correspond to the environmental sustainability classes of poor, fair, moderate, good, and excellent, respectively. Based on this, we qualitatively and quantitatively analyzed the environmental sustainability of the Beijing-Tianjin-Hebei region in 2015 (Chen et al., 2019). At the city scale, we quantitatively analyzed the distribution of the CEI of 13 cities in the Beijing-Tianjin-Hebei urban agglomeration in 2015 using methods such as zonal statistics.

\subsubsection{Spatiotemporal dynamic characteristics}

We calculated the CEI at seven time points from 1985 to 2015 based on the remote sensing images synthesized by the GEE and obtained the spatial distribution characteristics and dynamic change patterns of the CEI in the Beijing-Tianjin-Hebei region. Then, we classified the environmental sustainability of the study area into five quality grades and analyzed the dynamic change patterns of each quality grade for the entire Beijing-Tianjin-Hebei region and the city scale. Finally, we analyzed the changes in the environmental sustainability of the Beijing-Tianjin-Hebei urban agglomeration over the past 30 years by detecting the changes in the quality grades for the graded results from 1985 to 2015 .

\section{Results}

\subsection{Environmental Sustainability of the urban agglomeration in 2015}

The average CEI of the Beijing-Tianjin-Hebei urban agglomeration in 2015 was 0.672 , indicating that the agglomeration had a good environmental sustainability. As for the spatial distribution, the CEI was higher in the southeast and northeast and lower in the northwest of the region (Fig. 4a). Approximately $65 \%$ of the areas had excellent and good environmental sustainability quality grades and were mainly in Hengshui, Handan, and Xingtai in the southeast and northeast of Beijing-Tianjin-Hebei (Fig. 4b). The areas that had poor and fair sustainability quality grades accounted for $19 \%$ and were 
mainly concentrated in Zhangjiakou in the northwestern region (Fig. 4b).

At the city scale, the CEIs of more than half of the cities in the Beijing-Tianjin-Hebei region was higher than the average of the entire region. Among these cities, the CEIs of 7 cities, namely, Chengde, Hengshui, Qinhuangdao, Beijing, Handan, Xingtai, and Tangshan, were higher than the regional average of 0.672 . The highest value was 0.715 in Chengde, which was $6.5 \%$ higher than the regional average. However, the CEIs of the other six cities were below 0.672. The lowest value was 0.613 in Zhangiiakou, which was only $91.2 \%$ of the average value of the entire region (Fig. 5).

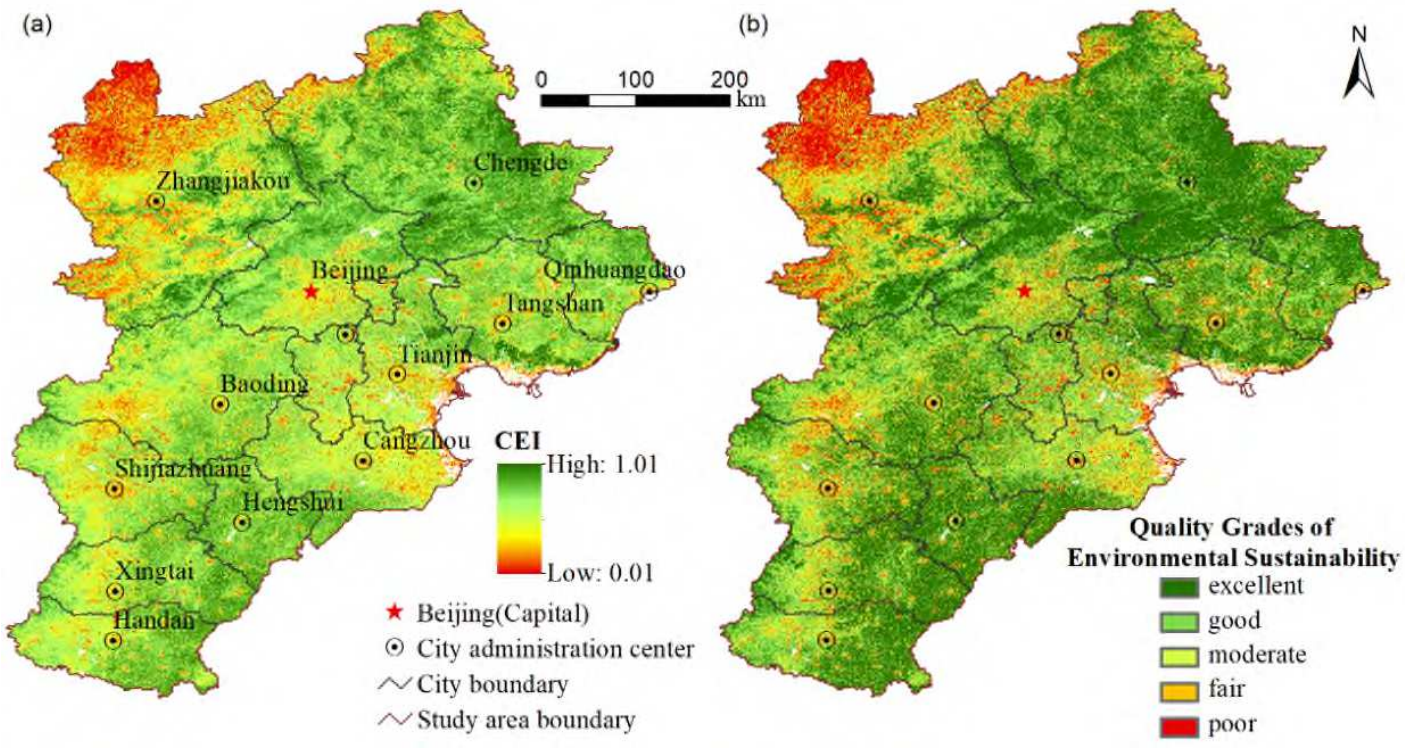

Fig. 4. Spatial distribution of the CEIs and environmental sustainability quality grades in 2015

(a: CEI value; b: five grades of the CEI)

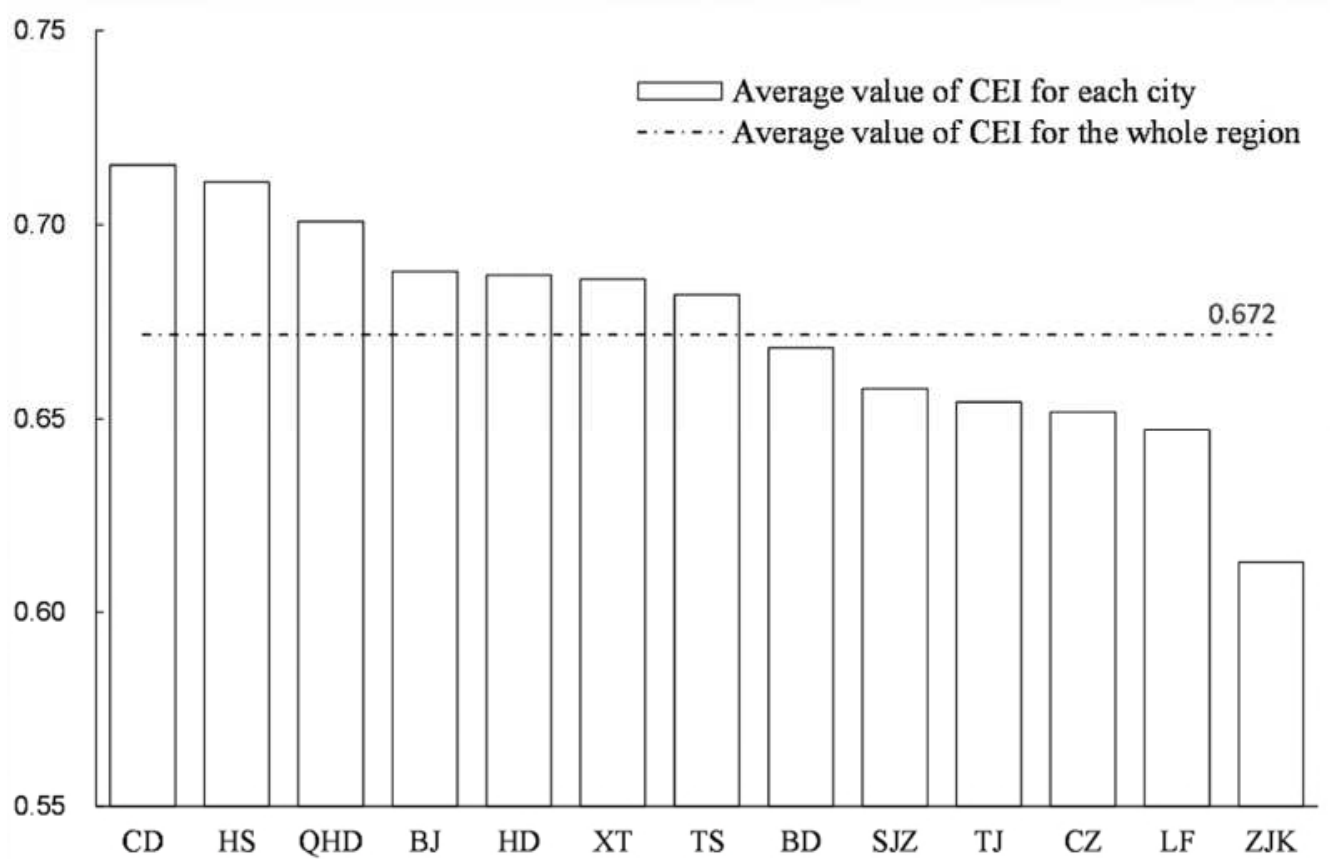

Fig. 5. CEIs of 13 cities from the Beijing-Tianjin-Hebei urban agglomeration in 2015. Note: The abbreviations for the 13 cities are as follows: Chengde (CD), Hengshui (SH), Qinhuangdao (QHD), Beijing (BJ), Handan (HD), Xingtai (XT), Tangshan (TS), Baoding (BD), Shijiazhuang (SJZ), Tianjin (TJ), Cangzhou (CZ), Langfang (LF), and Zhangjiakou (ZJK). 


\subsection{CEI dynamics from 1985 to 2015}

Over the past 30 years, the environmental sustainability of the Beijing-Tianjin-Hebei urban agglomeration showed a trend of rising, falling, and rising again (Fig. 6). From 1985 to 1990, the CEI rose from 0.621 to 0.631 with an increased rate of $1.6 \%$. However, from 1990 to 2000, the CEI decreased by $2.1 \%$, from 0.631 to the lowest value of 0.618 . Then, from 2000 to 2015 , the CEI rose to the highest value of 0.672 , increasing by $8.7 \%$ compared to 2000 . As for the distribution of the CEI, the differences in environmental sustainability were significant in the study area. The maximum values of the CEIs in the seven target years ranged from 0.80-0.90, the minimum values ranged from $0.35-0.47$, and the mean and median values fluctuated between 0.60 and 0.70 . In addition, the median and mean values of the CEIs for the seven years did not exceed 0.02, and the upper and lower quartiles were almost symmetrical around the means and medians, which means that the statistical distribution of the CEIs in the BeijingTianjin-Hebei region were approximately normal. Therefore, the mean and standard deviation can be used as references when grading the environmental sustainability quality.

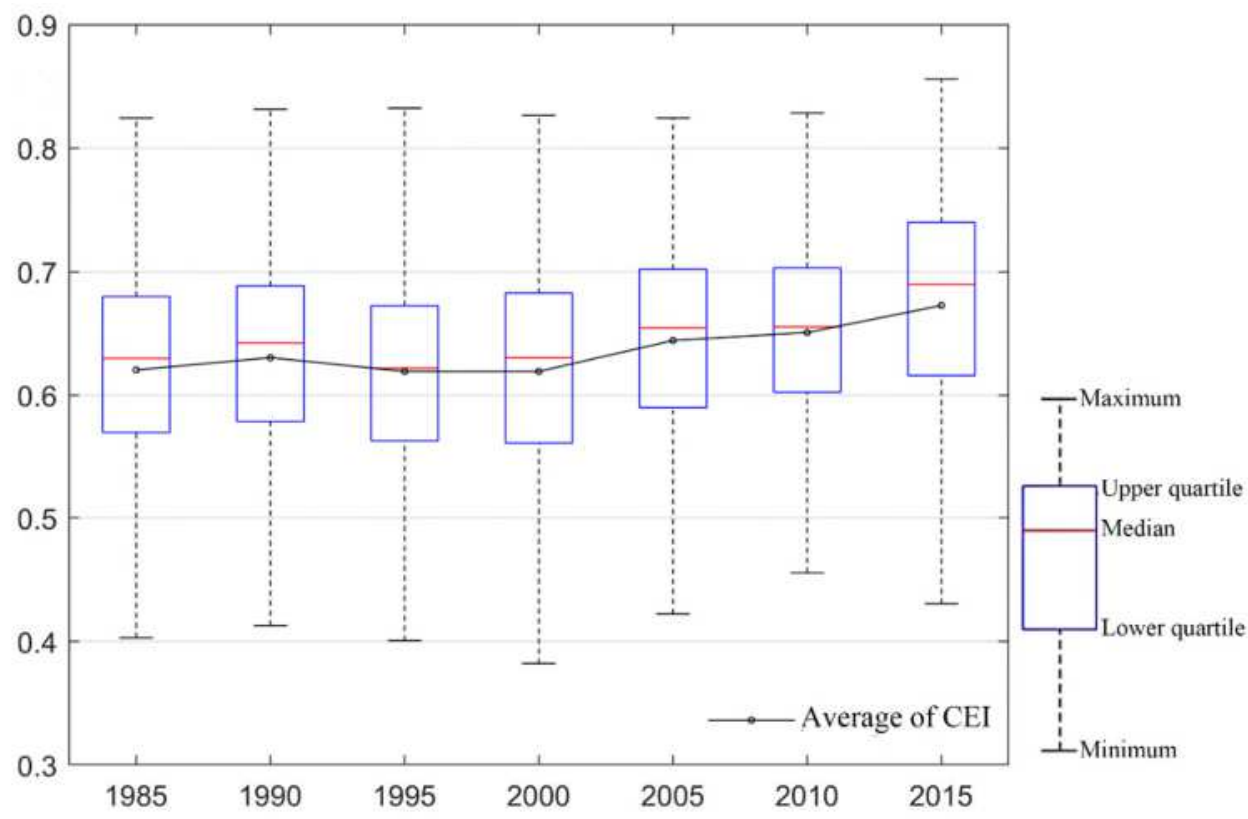

Fig. 6. Box plot of the CEI for the Beijing-Tianjin-Hebei urban agglomeration from 1985 to 2015.

Note: We did not show the outliers in the figure.

Based on the results of the environmental sustainability quality grading, the trend of change in the areas of "excellent" quality grades was the same as the trend of the CEI in Beijing-Tianjin-Hebei urban agglomeration: rising, then falling, then rising again. The area with "good" quality fluctuated between $22.6 \%$ and $32.8 \%$, and the area with "moderate" quality decreased from $27.6 \%$ to $15.8 \%$. The areas of the "poor" and "fair" quality classes showed the same trend: first increasing and then decreasing (Fig. 7). 


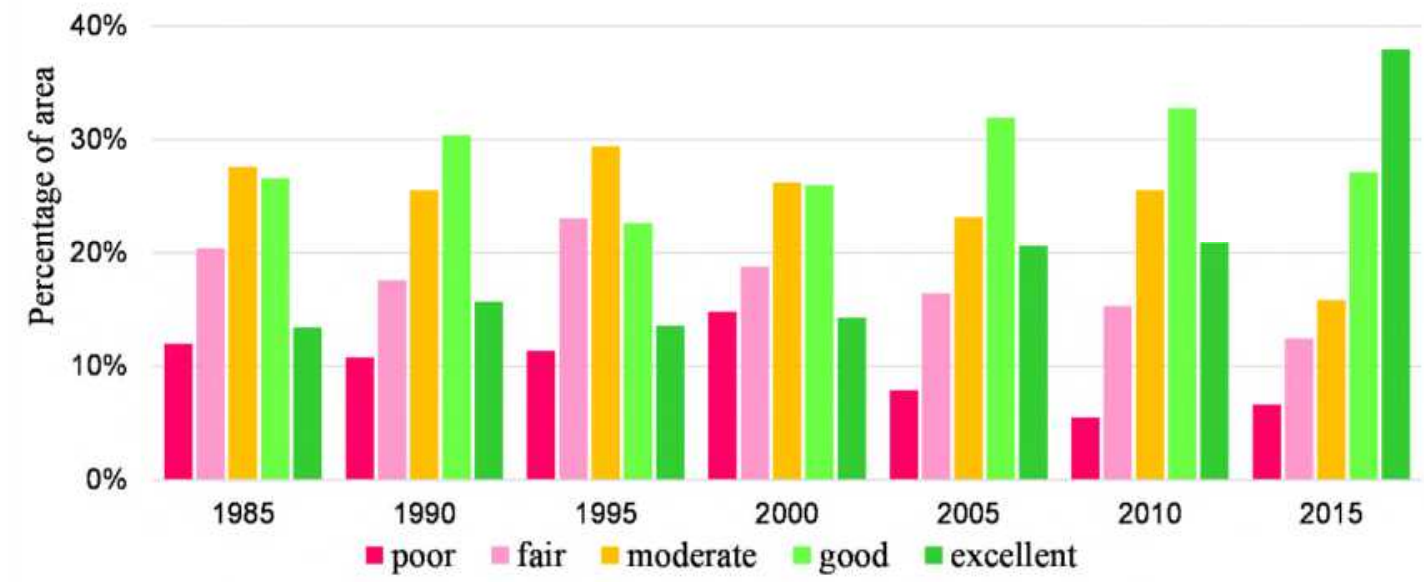

Fig. 7 Dynamics of CEI grading in the Beijing-Tianjin-Hebei urban agglomeration from 1985 to 2015.

In addition, the extent of areas in which environmental sustainability improved was much greater than the extent of areas in which it worsened in the Beijing-Tianjin-Hebei region. The areas where environmental sustainability improved comprised more than half of the region (Fig. 8). Approximately $56 \%$ of the regions experienced an increase in environmental sustainability quality, $12 \%$ experienced a decrease, and $32 \%$ remained stable. The areas with considerable improvements in quality grades were mainly located in Xingtai, Hengshui, and Cangzhou in the southeastern Beijing-Tianjin-Hebei urban agglomeration. The northwestern and northeastern areas experienced slight improvements. The areas that worsened were mainly concentrated in Beijing, Tianjin and Shijiazhuang.

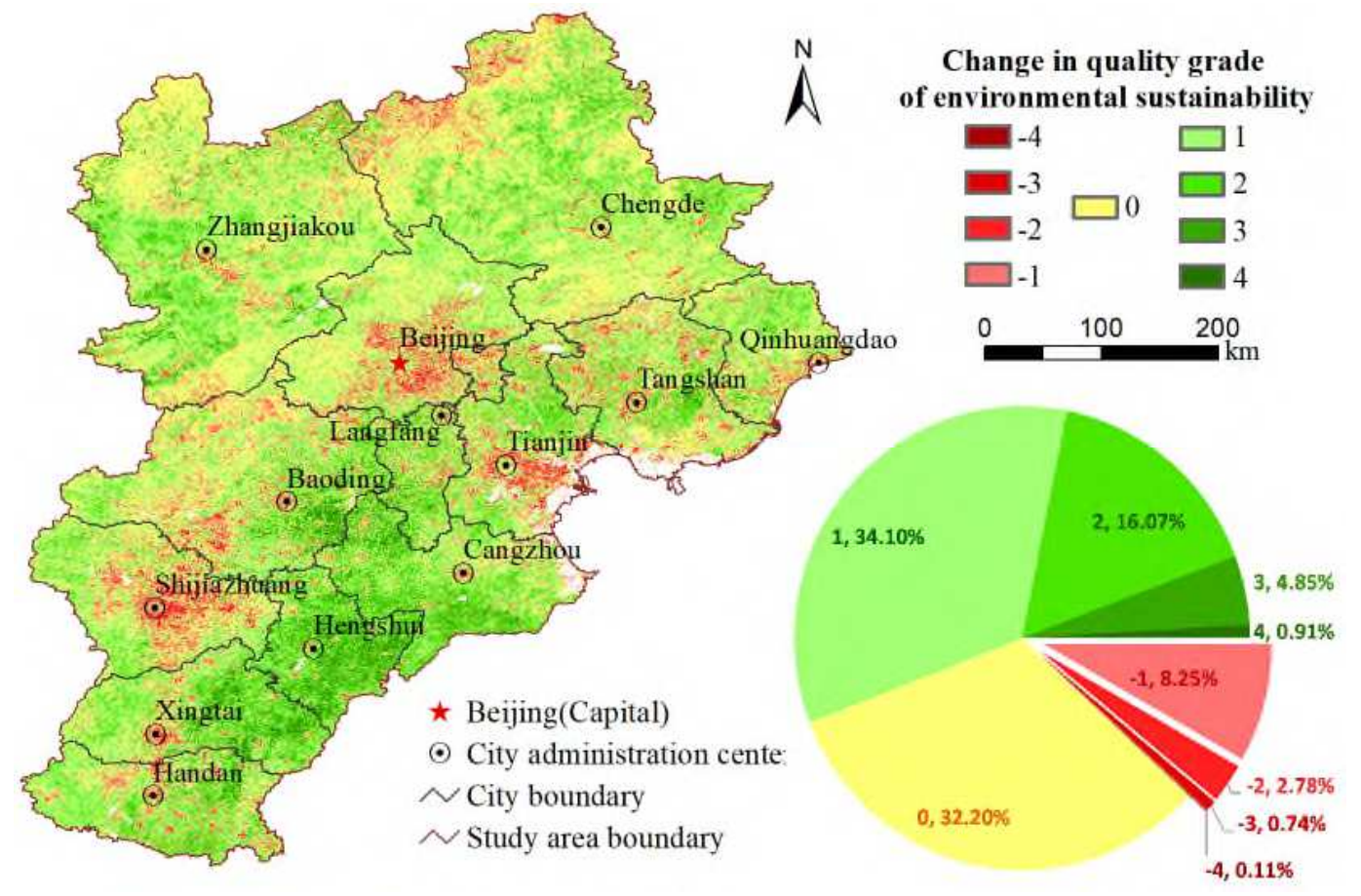

Fig. 8. Changes in quality grades of environmental sustainability from 1985 to 2015.

At the city scale, except for Tangshan and Shijiazhuang, the changes in the CEIs in the remaining 11 cities first increased, then decreased, and then increased again. The lowest CEI for each city generally 
occurred in 1995 or 2000 while the highest CEIs occurred in 2015. The CEI in Shijiazhuang first decreased and then increased. The overall trend of the CEI in Tangshan was a gradual increase. Considering the magnitudes of the changes, we sorted the CEIs of 13 cities according to the extreme difference. We found that 3 cities, Beijing, Tianjin and Tangshan, had low magnitudes of change and high mean CEIs, which meant they had better environmental sustainability and less drastic changes. In contrast, Xingtai, Zhangjiakou and Hengshui had high fluctuations and low mean CEIs, which meant that their environmental sustainability was low and dramatically changed (Fig. 9).
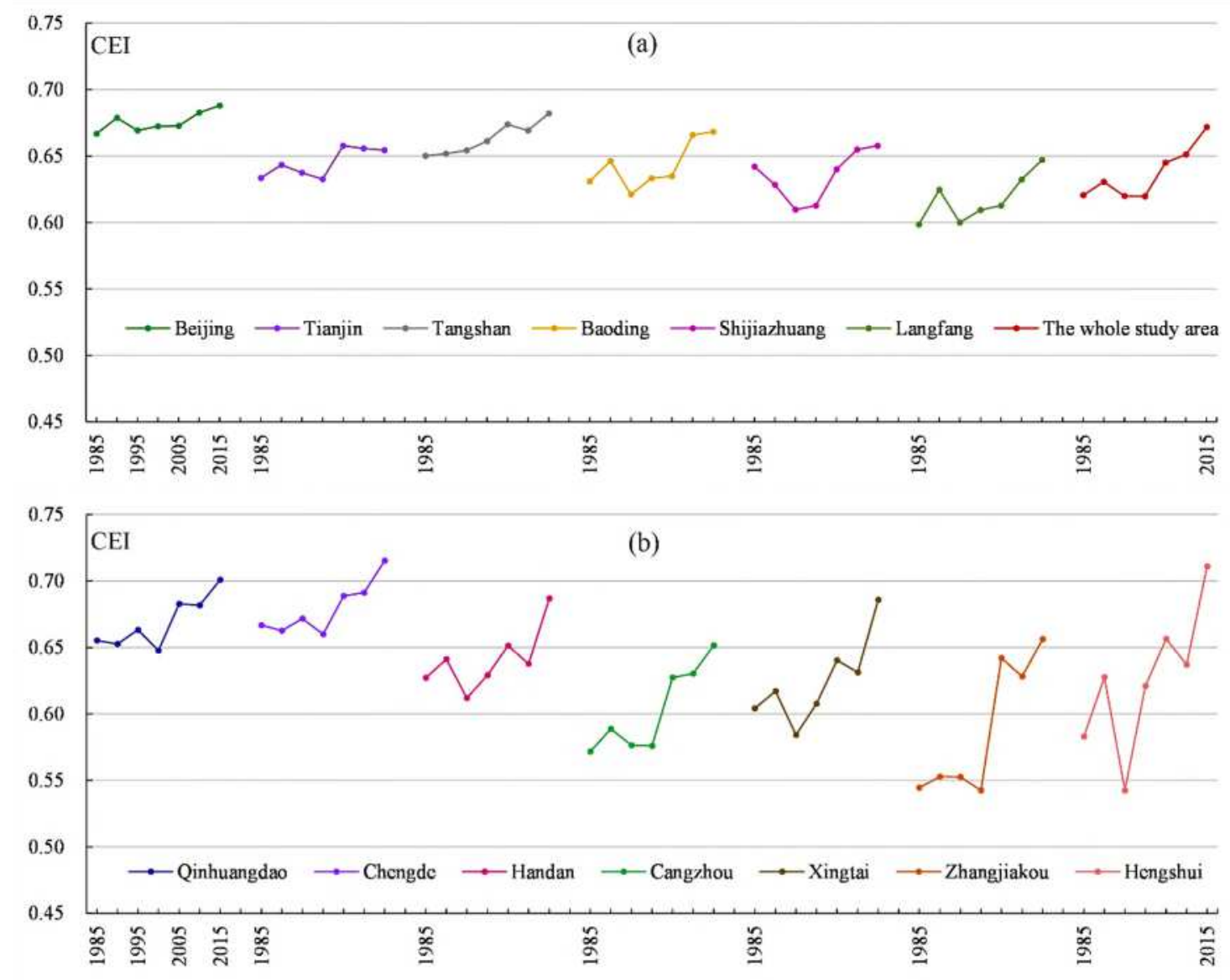

Fig. 9. Changes of the CEIs in 13 cities.

From the sustainability grading results of the 13 cities, we found that the 5 cities in the northeast Beijing-Tianjin-Hebei region (Beijing, Chengde, Qinhuangdao, Tangshan and Tianjin) had higher environmental sustainability grades than the other cities in the past 30 years overall. They had higher percentages of "excellent" and "good" quality grades and lower percentages of "poor" and "fair" grades compared to other cities. In addition, after grading the environmental sustainability of the 13 cities, the results showed that the trend and magnitude of the changes in each quality grade showed significant differences between the cities (Fig. 10). 


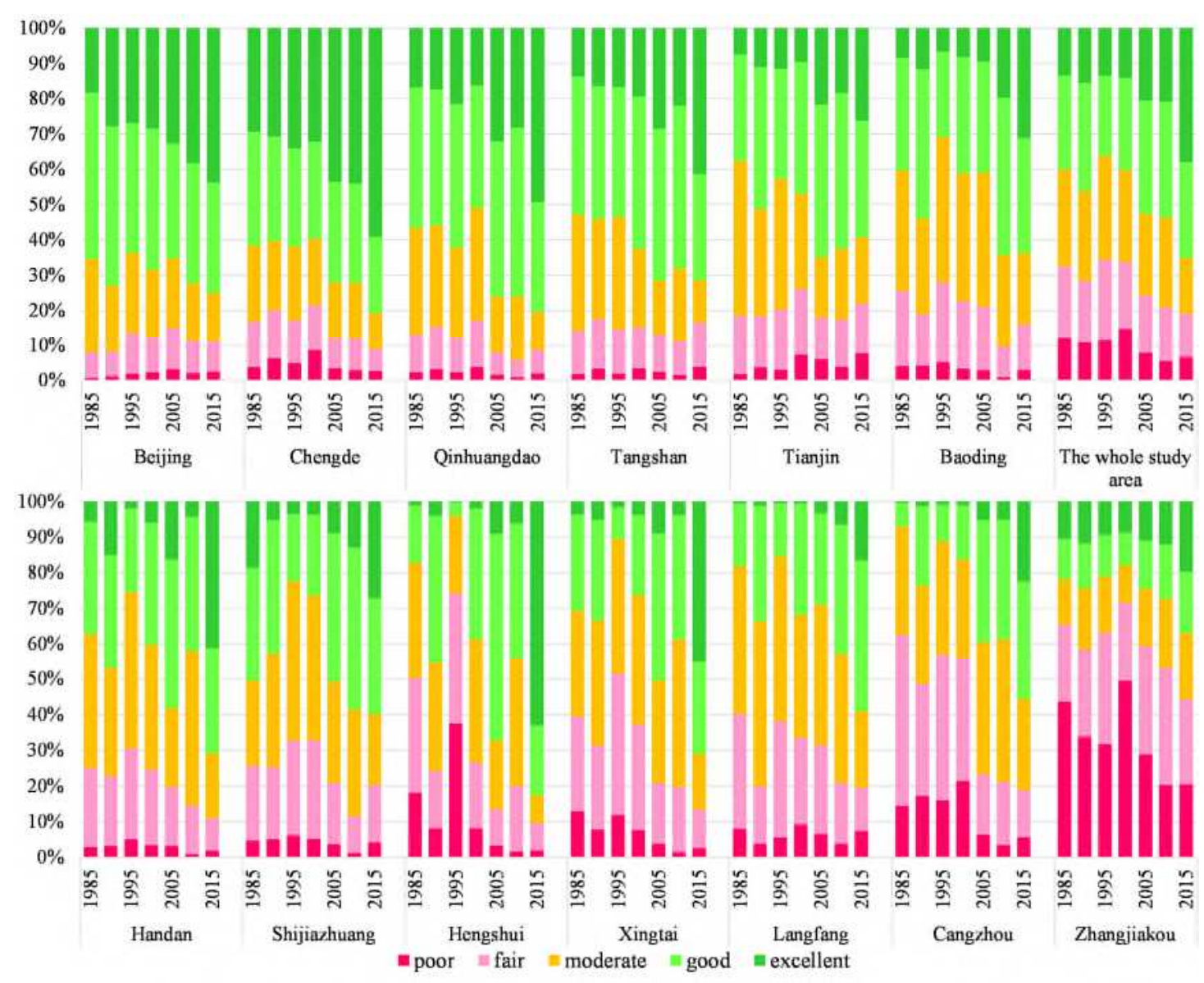

Fig. 10. Dynamics of the quality grades of environmental sustainability in 13 cities in Beijing-Tianjin-

Hebei.

\section{Discussion}

\subsection{Advantages of the developed method}

The method we developed in this study provides a new method and idea for effectively assessing the dynamic characteristics of the environmental sustainability of a region over long time scales. First, we developed the CEI, which can well reflect several dimensions of ecological and environment quality, such as greenness, wetness, dryness and heat. Compared to the classical RSEI, the CEI is more concise and intuitive. The RSEI calculated based on the principal component analysis sometimes leads to the dilemma that low values represent good ecological environment quality. In addition, the first principal component in the transformation may not guarantee a high contribution rate (previous studies with a varying level of contribution rate between $60 \%$ and $90 \%$ ), and the contribution rate of the first principal component gradually decreases as the number of indicators increases (Xu, 2013a; Shan et al., 2019; Xu et al., 2019). In our study, the NDVI and WET were used as positive indicators, and the NDBSI and LST were used as negative indicators. These indices were calculated using different normalization formulas. Then, we developed the CEI by calculating the geometric mean of the four indicators after normalization. This method combines qualitative and quantitative aspects, which ensures that a high CEI indicates good environmental sustainability. Taking 2015 as an example, comparing the spatial distribution of the CEI with 4 indicators (Figs. 4 and 11), we found that Zhangjiakou city had low vegetation cover (low NDVI), low wetness (low WET), high bare soil cover (high NDBSI), and a high surface temperature (high LST), 
corresponding to its poor environmental sustainability (low CEI).
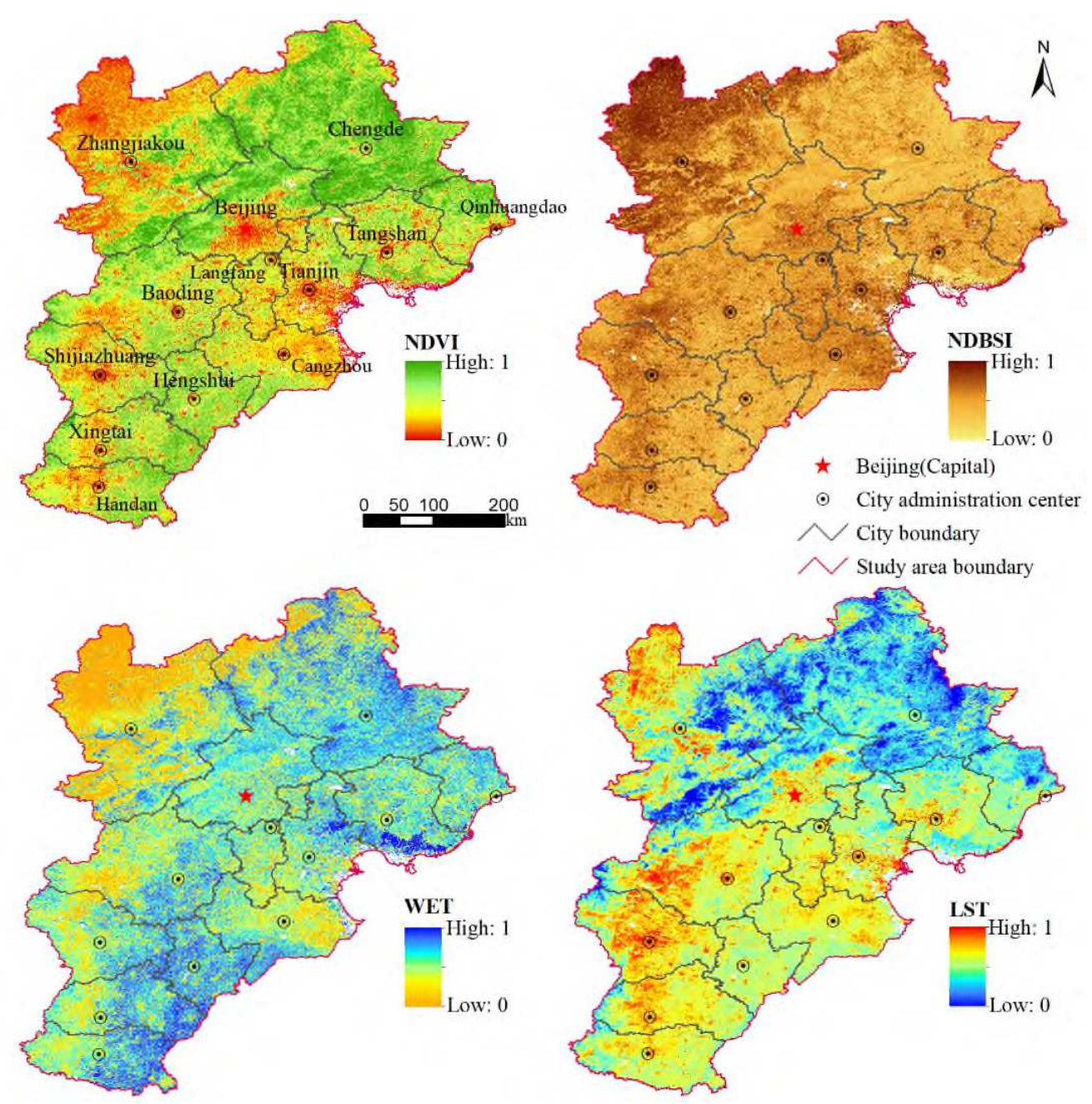

Fig. 11. Comparison between the NDVI, NDBSI, WET and LST of the Beijing-Tianjin-Hebei urban agglomeration in 2015. Note: All four indicators are normalized using the maximum-minimum normalization method

To evaluate the validity of the CEI, we used two more indicators, the RSEI and $\mathrm{RSEI}_{\mathrm{wi}}$, to quantitatively assess the CEI. The RSEI was calculated using principal component analysis (Xu, 2013a), and the RSEIwi was calculated using the entropy weight method (Chen et al., 2021). The results showed that the CEI had a significant correlation with the results calculated by the classical RSEI model or the improved RSEI model (RSEI ${ }_{w i}$ ) (Fig. 12). The correlation coefficient between the CEI and RSEI was 0.86, and the correlation coefficient between the CEI and RSEI $\mathrm{wi}_{\mathrm{i}}$ was 0.99 , which proved that our method was scientific and effective and could well reflect the state of the ecological environment of urban agglomerations. 


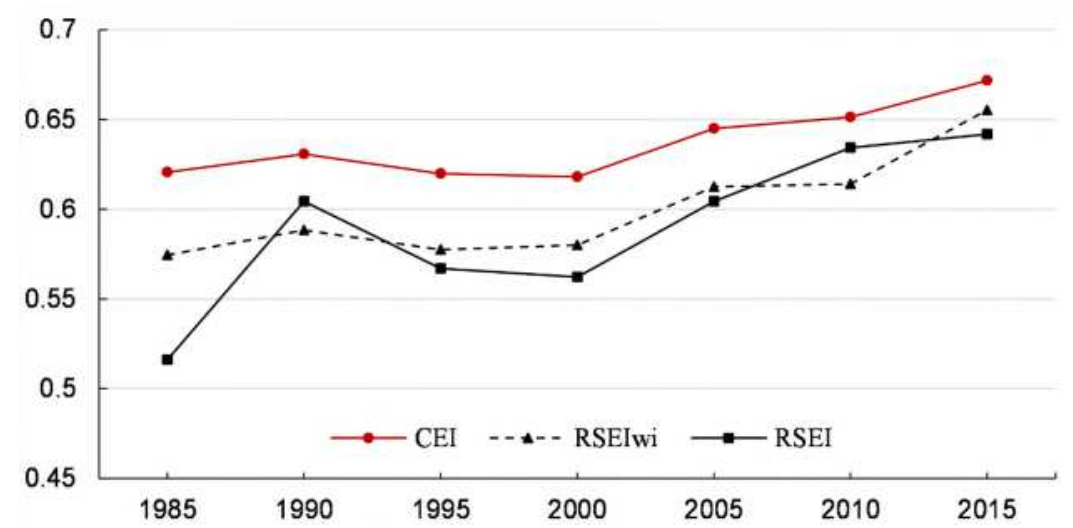

Fig. 12. Comparison of the CEI, RSEI and RSEI $\mathrm{wi}_{\text {. }}$

The CEI had good correlations with most environmental indicators in the Environmental Statistics Yearbook (Table 1), which further proved the validity of the CEI in measuring the environmental sustainability of cities. Due to data availability, we acquired the natural resource consumption data and pollutant emission data of 13 cities in the Beijing-Tianjin-Hebei urban agglomeration from 2000 to 2015 and analyzed their correlation with the CEI. The results showed that there was a strong correlation between the CEI and most statistical indicators in the Beijing-Tianjin-Hebei urban agglomeration. For example, the correlation coefficients of CEI and Industrial solid waste utilization and urban sewage treatment rate were in the range of $0.20-0.96$ and $0.61-0.97$, respectively, showing a strong positive correlation. However, the correlation coefficients with industrial wastewater emissions and $\mathrm{SO}_{2}$ emissions showed different correlations in different cities, and the overall correlation was not significant.

Finally, we developed the CEI with the GEE platform, which has great advantages in the online access, preprocessing and exponential computing of remote sensing big data. First, the GEE is able to access 5206 online pieces of data and over 1200 GB of remote sensing data from the USGS between 1983 and 2016, and the GEE is free from the limitation of local computer data storage. Moreover, using the GEE to conduct preprocessing operations, including cloud mask and image integration, eliminates complicated offline manual processing. In addition, the GEE uses Google's high-performance servers for parallel cloud computing, which can quickly conduct exponential calculations and improve the data processing efficiency.

Table 1 Correlation coefficients of the CEI and various statistical indicators from 2000 to 2015

\begin{tabular}{ccccccc}
\hline City & $\begin{array}{c}\text { Water } \\
\text { consumption } \\
\text { per capita } \\
\left(\mathrm{m}^{3}\right)\end{array}$ & $\begin{array}{c}\text { Industrial } \\
\text { wastewater } \\
\text { emissions } \\
\left(\mathrm{km}^{3)}\right.\end{array}$ & $\begin{array}{c}\text { Industrial } \\
\mathrm{SO}_{2} \\
\text { emissions } \\
\left(\mathrm{km}^{3}\right)\end{array}$ & $\begin{array}{c}\text { Urban green } \\
\text { space per } \\
\text { capita }\left(\mathrm{m}^{2}\right)\end{array}$ & $\begin{array}{c}\text { Industrial } \\
\text { solid waste } \\
\text { utilization \% }\end{array}$ & $\begin{array}{c}\text { Urban } \\
\text { sewage } \\
\text { treatment } \\
\text { rate }\end{array}$ \\
\hline Beijing & -0.84 & -0.75 & $-0.96^{*}$ & 0.87 & 0.61 & 0.83 \\
Tianjin & -0.56 & 0.56 & -0.36 & $0.99^{* *}$ & 0.90 & 0.72 \\
Shijiazhuang & $-0.98^{*}$ & -0.08 & -0.13 & $0.97 *$ & 0.87 & $0.96^{*}$ \\
Tangshan & -0.61 & -0.79 & -0.16 & 0.57 & 0.81 & 0.78 \\
Qinhuangdao & -0.72 & $0.98^{*}$ & 0.26 & 0.77 & 0.86 & 0.94 \\
Handan & -0.68 & -0.63 & -0.86 & 0.70 & 0.64 & 0.63 \\
Xingtai & -0.58 & $0.99 * *$ & -0.02 & 0.73 & 0.20 & 0.90 \\
Baoding & $-0.99^{*}$ & -0.49 & -0.35 & 0.38 & 0.91 & 0.93
\end{tabular}




\begin{tabular}{ccccccc} 
Zhangjiakou & -0.52 & 0.08 & 0.59 & -0.48 & $0.96^{*}$ & 0.81 \\
Chengde & -0.7 & $-0.96^{*}$ & -0.38 & 0.81 & 0.86 & 0.97 \\
Cangzhou & -0.87 & 0.41 & 0.19 & $0.96^{*}$ & 0.87 & 0.92 \\
Langfang & $-0.96^{*}$ & 0.53 & 0.34 & 0.34 & 0.69 & 0.93 \\
Hengshui & -0.38 & -0.73 & 0.04 & -0.50 & 0.86 & 0.61 \\
\hline
\end{tabular}

* Correlation is significant at the 0.05 level (2-tailed).

** Correlation is significant at the 0.01 level (2-tailed).

\subsection{Future perspectives}

We developed a method for regional sustainability quantitative assessment using the GEE based on the environmental sustainability assessment framework proposed by the UNCSD. The method can quickly analyze the dynamics of regional environmental sustainability over a long time period and in several dimensions. Our method can be well transferred and applied to other regions. However, there are many shortcomings of the method that could be improved.

First, when calculating the composite index, the CEI is not yet able to directly reflect the biodiversity of the ecosystem and the air quality of the atmosphere. At present, we only established indirect links to biodiversity and air quality through the vegetation status. In the future, it is expected that a new comprehensive environmental index can be established by creating remote sensing indicators representing biodiversity and air quality, such as the dynamic habitat index and $\mathrm{PM}_{2.5}$ concentration (Coops et al., 2008; Wan et al., 2021). Second, we developed the CEI by calculating the geometric means of four indicators: the NDVI, NDBSI, WET and LST. However, the elements of the ecological environment are not independent and juxtaposed with each other, so there must be interactions among the indicators of the four dimensions of the CEI. It is expected that new methods that integrate the indicators of various dimensions will be developed in the future. Third, the method we adopted in grading the CEI determined the grading limits based on the distribution characteristics of the data. The grading results were not examined and verified with the actual situations, leading to possible errors. Finally, we have not yet analyzed the driving factors of the CEI. It is expected that in the future, the physical data (temperature and precipitation) and socioeconomic data (population, GDP, pollutant emissions and land use) of the Beijing-Tianjin-Hebei urban agglomeration in a long time series can be used to analyze the driving factors of ecological and environmental quality changes.

\section{Conclusions}

In this study, we developed a method which can overcome the difficulty in accessing, storing and processing environmental remote sensing big data to achieve the environmental sustainability monitoring and assessment. Specifically, we used the GEE platform to collect 5206 Landsat images of the BeijingTianjin-Hebei urban agglomeration from 1985 to 2015. Then, we developed a compressive environmental index based on the UN sustainability assessment framework for assessing environmental sustainability.

The overall environmental sustainability of the Beijing-Tianjin-Hebei urban agglomeration experienced a change trend of rising, then falling, and then rising again from 1985 to 2015 . The environmental sustainability of cities in the northeastern part of the urban agglomeration (Beijing, Chengde, Qinhuangdao, and Tangshan) has been better overall than that of cities in other regions, and the deteriorated areas were mainly in Beijing, Tianjin and Shijiazhuang. Therefore, the improvement of 
environmentally fragile areas such as Zhangjiakou should be maintained and continued to promote further sustainable environmental development in the future ecological environmental construction of the Beijing-Tianjin-Hebei urban agglomeration.

\section{Acknowledgements}

We express our gratitude to the anonymous reviewers and editors for their insightful and critical comments, which have improved the quality of the manuscript. This research was supported in part by the National Natural Science Foundation of China [Grant No. 41971225], and the Beijing Municipal Natural Science Fund [Grant No. 8192027].

\section{Author contribution}

Xianwang Xia: data processing and analysis, writing — original draft preparation, and visualization. Chentai Jiao: data processing and analysis.

Shixiong Song: data processing and analysis, conceptualization and methodology.

Ling Zhang: writing — review and editing, and methodology.

Xingyun Feng: writing — review and editing.

Qingxu Huang: conceptualization, supervision, and writing — review and editing.

\section{Availability of data and materials}

The datasets generated and/or analyzed during the current study are not publicly available due to the sensitive nature of the raw data but are available from the corresponding author on reasonable request. 


\section{References}

Baig, M. H. A., Zhang, L., Shuai, T., \& Tong, Q. (2014). Derivation of a tasselled cap transformation based on Landsat 8 at-satellite reflectance. Remote Sensing Letters, 5(5), 423-431.

Brundtland, G. H. (1987). Our common future-Call for action. Environmental Conservation, 14(4), 291-294.

Chen, W., Huang, H., Tian, Y. \& Du, Y. (2019). Monitoring and assessment of the eco-environment quality in the Sanjiangyuan region based on Google Earth Engine. Journal of Geo-information Science, 21(09),1382-1391(in Chinese).

Cheng, L., Wang, Z., Tian, S., Liu, Y., Sun, M., \& Yang, Y. (2021). Evaluation of eco-environmental quality in Mentougou District of Beijing based on improved remote sensing ecological index. Chinese Journal of Ecology, 40(04),1177-1185(in Chinese).

Coops, N. C., Wulder, M. A., Duro, D. C., Han, T., \& Berry, S. (2008). The development of a Canadian dynamic habitat index using multi-temporal satellite estimates of canopy light absorbance. Ecological Indicators, 8(5), 754-766.

Crist, E. P. (1985). A TM tasseled cap equivalent transformation for reflectance factor data. Remote sensing of Environment, 17(3), 301-306.

Duguay-Tetzlaff, A., Bento, V. A., Göttsche, F. M., Stöckli, R., Martins, J., Trigo, I., ... \& Kunz, H. (2015). Meteosat land surface temperature climate data record: Achievable accuracy and potential uncertainties. Remote Sensing, 7(10), 13139-13156.

Ermida, S. L., Soares, P., Mantas, V., Göttsche, F. M., \& Trigo, I. F. (2020). Google earth engine opensource code for land surface temperature estimation from the landsat series. Remote Sensing, 12(9), 1471.

Estoque, R. C. (2020). A review of the sustainability concept and the state of SDG monitoring using remote sensing. Remote Sensing, 12(11), 1770.

Fairbanks, D. H., \& McGwire, K. C. (2004). Patterns of floristic richness in vegetation communities of California: regional scale analysis with multi-temporal NDVI. Global Ecology and Biogeography, 13(3), 221-235.

Gandhi, G. M., Parthiban, S., Thummalu, N., \& Christy, A. (2015). Ndvi: Vegetation change detection using remote sensing and gis-A case study of Vellore District. Procedia computer science, 57, 11991210.

Goward, S. N., Xue, Y., \& Czajkowski, K. P. (2002). Evaluating land surface moisture conditions from the remotely sensed temperature/vegetation index measurements: An exploration with the simplified simple biosphere model. Remote sensing of environment, 79(2-3), 225-242.

Hansen, M. C., Potapov, P. V., Moore, R., Hancher, M., Turubanova, S. A., Tyukavina, A., ... \& Townshend, J. (2013). High-resolution global maps of 21st-century forest cover change. science, 342(6160), 850-853.

He C, Gao B, Huang Q, Ma Q, Dou Y (2017) Environmental degradation in the urban areas of China: Evidence from multi-source remote sensing data. Remote Sensing of Environment 193: 65-75.

$\mathrm{Hu}, \mathrm{X}$., \& Xu, H. (2018). A new remote sensing index for assessing the spatial heterogeneity in urban ecological quality: A case from Fuzhou City, China. Ecological Indicators, 89, 11-21.

Kumar, L., \& Mutanga, O. (2018). Google Earth Engine applications since inception: Usage, trends, and potential. Remote Sensing, 10(10), 1509.

Liu, D., \& Hao, S. (2017). Ecosystem health assessment at county-scale using the pressure-state-response framework on the Loess Plateau, China. International Journal of Environmental Research and Public 
Health, 14(1), 2.

Midekisa, A., Holl, F., Savory, D. J., Andrade-Pacheco, R., Gething, P. W., Bennett, A., \& Sturrock, H. J. (2017). Mapping land cover change over continental Africa using Landsat and Google Earth Engine cloud computing. PloS one, 12(9), e0184926.

Olafsson, S., Cook, D., Davidsdottir, B., \& Johannsdottir, L. (2014). Measuring countries' environmental sustainability performance-A review and case study of Iceland. Renewable and Sustainable Energy Reviews, 39, 934-948.

Rikimaru, A., Roy, P. S., \& Miyatake, S. (2002). Tropical forest cover density mapping. Tropical ecology, 43(1), 39-47.

Senay, G. B., \& Elliott, R. L. (2000). Combining AVHRR-NDVI and landuse data to describe temporal and spatial dynamics of vegetation. Forest Ecology and management, 128(1-2), 83-91.

Shan, W., Jin, X., Meng, X., Yang, X., Xu, Z., Gu, Z. \& Zhou, Y. (2019). Dynamical monitoring of ecological environment quality of land consolidation based on multi-source remote sensing data. Transactions of the Chinese Society of Agricultural Engineering, 35(01), 234-242(in Chinese).

Shruti, S., Singh, P. K., \& Ohri, A. (2021). Evaluating the environmental sustainability of smart cities in india: The design and application of the Indian smart city environmental sustainability index. Sustainability, 13(1), 327.

Sutton, P. C. (2003). An empirical environmental sustainability index derived solely from nighttime satellite imagery and ecosystem service valuation. Population and Environment, 24(4), 293-311.

UN, 2007. Indicators of Sustainable Development: Guidelines and Methodologies. thirded. United Nations, New York.

UNDP, 2014. Human Development Report 2014. Sustaining Human Progress: Reducing Vulnerabilities and Building Resilience. United Nations, New York.

Ustin, S. L. (Ed.). (2004). Manual of remote sensing, remote sensing for natural resource management and environmental monitoring (Vol. 4). John Wiley \& Sons.

Wan, H., Huo, F., Niu, Y., Zhang, W. \& Zhang, Q. (2021). Dynamic monitoring and analysis of ecological environment change in Cangzhou city based on RSEI model considering PM2.5 concentration. Progress in Geophysics, 36(03),953-960 (in Chinese).

Wang, Q. (2021). Progress of environmental remote sensing monitoring technology in China and some related frontier issues. National Remote Sensing Bulletin, 25(01), 25-36 (in Chinese).

Wang, Z., Liang, L., Sun, Z., \& Wang, X. (2019). Spatiotemporal differentiation and the factors influencing urbanization and ecological environment synergistic effects within the Beijing-TianjinHebei urban agglomeration. Journal of environmental management, 243, 227-239.

Wu, J. (2013). Landscape sustainability science: ecosystem services and human well-being in changing landscapes. Landscape ecology, 28(6), 999-1023.

$\mathrm{Xu}, \mathrm{H}$. (2005). A study on information extraction of water body with the modified normalized difference water index (MNDWI). Journal of Remote Sensing, 5, 589-595.

$\mathrm{Xu}, \mathrm{H}$. (2008). A new index for delineating built-up land features in satellite imagery. International journal of remote sensing, 29(14), 4269-4276.

$\mathrm{Xu}, \mathrm{H}$. (2013a). A remote sensing urban ecological index and its application. Acta Ecologica Sinica, 33(24), 7853-7862 (in Chinese).

$\mathrm{Xu}$, H. (2013b). A remote sensing index for assessment of regional ecological changes. China Environmental Science, 33(5), 889-897.

$\mathrm{Xu}, \mathrm{H}$. (2013c). Assessment of ecological change in soil loss area using remote sensing technology. 
Transactions of the Chinese Society of Agricultural Engineering, 29(7), 91-97.

Xu, H., Wang, Y., Guan, H., Shi, T., \& Hu, X. (2019). Detecting ecological changes with a remote sensing based ecological index (RSEI) produced time series and change vector analysis. Remote Sensing, 11(20), 2345.

Zhu, C., Zhang, X. \& Huang, Q. (2018). Lake hydrological information estimation based on remote sensing. Journal of China Hydrology, 38(05), 29-33(in Chinese). 